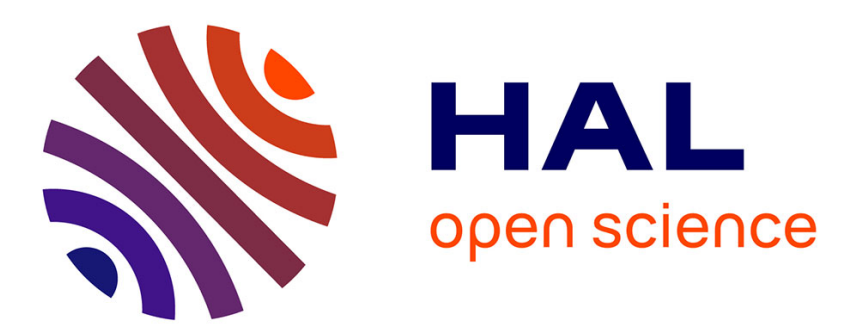

\title{
Wave control on the rhythmic development of a wide estuary mouth sandbank: A process-based modelling study
}

Thomas Guérin, Xavier Bertin, Eric Chaumillon

\section{- To cite this version:}

Thomas Guérin, Xavier Bertin, Eric Chaumillon. Wave control on the rhythmic development of a wide estuary mouth sandbank: A process-based modelling study. Marine Geology, 2016, 380, pp.79 89. 10.1016/j.margeo.2016.06.013 . hal-01431341

\section{HAL Id: hal-01431341 \\ https://hal.science/hal-01431341}

Submitted on 10 Jan 2017

HAL is a multi-disciplinary open access archive for the deposit and dissemination of scientific research documents, whether they are published or not. The documents may come from teaching and research institutions in France or abroad, or from public or private research centers.
L'archive ouverte pluridisciplinaire HAL, est destinée au dépôt et à la diffusion de documents scientifiques de niveau recherche, publiés ou non, émanant des établissements d'enseignement et de recherche français ou étrangers, des laboratoires publics ou privés. 


\title{
Wave control on the rhythmic development of a wide estuary mouth sandbank : a process-based modelling study
}

\author{
Thomas Guérin $^{\mathrm{a}}$, Xavier Bertin ${ }^{\mathrm{a}}$, Eric Chaumillon ${ }^{\mathrm{a}}$ \\ ${ }^{a}$ UMR 7266 LIENSs CNRS-Université de La Rochelle, Institut du Littoral et de \\ l'Environnement, 2 rue Olympe de Gouges, 17000 La Rochelle, France
}

\begin{abstract}
This study presents the numerical hindcast of the morphological changes and stratigraphy of a wide estuary mouth sandbank located along the French Atlantic coast (Marennes-Oléron Bay), and primarily investigates the respective contribution of tide and waves to its pluri-decadal evolution. Firstly, the morphodynamic hindcast appears strongly improved when tide and waves are considered in the forcing rather than only tide. Secondly, the modelling results suggest that the strong seasonal variation of the wave climate in this area explains the rhythmic lateral accretion of the bank (i.e. normal to the currents main direction) observed in seismic reflection profiles. The grain size variation in the area of sediment accretion is also characterized by a seasonal cycle. Finally, repetitive bathymetric surveys and seismic profiles revealed that the lateral accretion of the bank is associated with about one seismic reflector per year, which is in agreement with our modelling results when suggesting that these seismic reflectors are due to the seasonal variation of the grain size. These new results may be considered for the morphological evolution and the stratigraphy of other tidal sandbanks potentially affected by waves.
\end{abstract}

Keywords: Longe de Boyard sandbank; morphodynamic modelling; stratigraphy; wave action; multi-sized sediment; seismic reflector.

Email addresses: thomas.guerin@univ-lr.fr (Thomas Guérin), xavier.bertin@univ-lr.fr (Xavier Bertin), eric.chaumillon@univ-lr.fr (Eric Chaumillon)

Final post-refereeing version published in Marine Geology

10 janvier 2017 


\section{Introduction}

Sandbanks appear widely in coastal and shelf seas, where sand is abundant enough and hydrodynamic conditions are sufficient to move the sediment material. Understanding the evolution of these bed forms is important for coastal activities such as navigation and dredging, but also to quantify sediment exchange with adjacent shorelines. Due to the different classifications of sandbanks and ridges in the literature (e.g. Pattiaratchi and Collins, 1987; Swift et al., 1991 Dyer and Huntley, 1999, hereinafter DH99), some confusion has been observed in their terminology. In order to unify the approaches of marine geologists and physical oceanographers, DH99 proposed a classification of sandbanks and ridges which will be used in the present study.

Though the formation and maintenance of tide-dominated sandbanks like open shelf or headland associated sandbanks (type 1 and 3 in DH99, respectively) are well explained theoretically (e.g. Huthnance, 1982 , Signell and Harris 2000), estuary mouth sandbanks (type 2 in DH99), which include sandbanks emplaced in wide estuaries and in tidal inlets (ebb and flood deltas), have for a long time received less attention (DH99). More precisely, while the emergence of morphodynamic modelling provided a substantial improvement in the understanding of the processes responsible for the development and morphological changes of tidal inlets (e.g. Cayocca, 2001; Dastgheib et al., 2008; Dissanayake et al. 2009, Nahon et al. 2012), wide estuary mouth sandbanks have received very little attention, potentially because they are less frequent than ebb and flood deltas. Yet, these sandbanks are very interesting because their development in shallow waters and their exposure to waves could suggest that they may not be only tidally controlled.

Numerous studies have provided qualitative information on this type of sandbanks (e.g. Ludwick, 1974, Harris, 1988, Gómez and Perillo, 1992, Chaumillon et al., 2002, Kapsimalis et al., 2004) but, to our knowledge, no study has managed to quantify the respective contribution of tides and waves to the long-term 
morphodynamic of these sandbanks. In order to do so, process-based morphodynamic modelling systems appear nowadays as attractive tools since they allow to perform coastal morphodynamic simulations by coupling currents, waves, sediment transport, and bottom change. Moreover, the recent development of multi-class and multi-layer (MCML) methods in sediment transport models allows accounting for the granulometric heterogeneity of the sediment, and even computing numerical stratigraphy. One can cite the work of Geleynse et al. (2010), Geleynse et al. (2011) and Viparelli et al. (2014) who have successfully simulated the formation of river deltas and their stratigraphy. Nevertheless, such promising coupled approaches still have to be applied to other coastal environments, such as wide estuary mouth sandbanks.

In this study, a horizontally two-dimensional (2DH), unstructured grid, morphodynamicstratigraphic modelling system was used to investigate the respective contribution of tides and waves to the 40-year retrospective evolution (period 1960 to 2000) of a wide estuary mouth sandbank located along the French Atlantic coast in the Marennes-Oléron Bay. To this aim, two morphodynamic simulations starting with the bathymetry of 1960 were considered, the first including tidal forcing only and the second including tidal and waves forcing. The bathymetry of 2000 together with seismic data were then used to assess the morphological and stratigraphic numerical results.

In the next section, the study area is presented along with a summary of previous knowledge available for this sandbank. The morphodynamic modelling system is described in the third section, with emphasis on the MCML method which has been implemented into the sediment transport module. Finally, the confrontation between numerical results and field data are presented and discussed. 


\section{Study area}

\subsection{Geomorphic setting}

The Longe de Boyard Sandbank is a wide estuary mouth sandbank located along the French Atlantic coast, in the northern entrance of the MarennesOléron Bay (Fig. 1). It is about $8 \mathrm{~km}$ long and $2 \mathrm{~km}$ wide with a tide-dominated morphology (flood lobe), and its bed elevation ranges from about $-17 \mathrm{~m}$ from mean sea level (MSL) near the flanks up to $-3 \mathrm{~m}$ MSL at the southern end of the sandbank. The internal architecture of this sandbank was revealed by seismic profiling and three main seismic units were identified : an upper one characterized by fine and medium sand, lying on an old core of coarse sand and gravel, itself lying on a transgressive valley-fill (Chaumillon et al., 2002, 2008).

\subsection{Hydrodynamic setting}

This sandbank is subjected to a semi-diurnal, macrotidal regime with tidal range going from less than $2 \mathrm{~m}$ during neap tides up to more than $6 \mathrm{~m}$ during spring tides. The flood tidal prism is about $10 \%$ more than the ebb tidal prism at the northern entrance of the bay due to the connection of the Marennes-Oléron Bay with the ocean at both ends of the Oléron Island. The main incoming freshwater discharge is due to the Charente River, with a mean annual discharge of $70 \mathrm{~m}^{3} / \mathrm{s}$ (Toublanc et al. 2015). The dominant offshore wave conditions are characterized by significant wave heights ranging from 1 to $2 \mathrm{~m}$ and potentially exceeding $6 \mathrm{~m}$ during storms, peak periods ranging from $8 \mathrm{~s}$ to $12 \mathrm{~s}$, and waves coming from West to NorthWest. The Bay of Biscay is subjected to strong seasonal and interannual wave climate variations (Dodet et al., 2010), with winter periods potentially characterized by very energetic storm waves (Idier et al. 2006) episodically exceeding $10 \mathrm{~m}$ of significant wave height in deep water (Bertin et al., 2015).

\subsection{Previous knowledge on the sandbank}

From 1824 to 2000, an anticlockwise rotation of the sandbank was observed, with sediment accretion of its North-West (NW) and South-East (SE) parts 

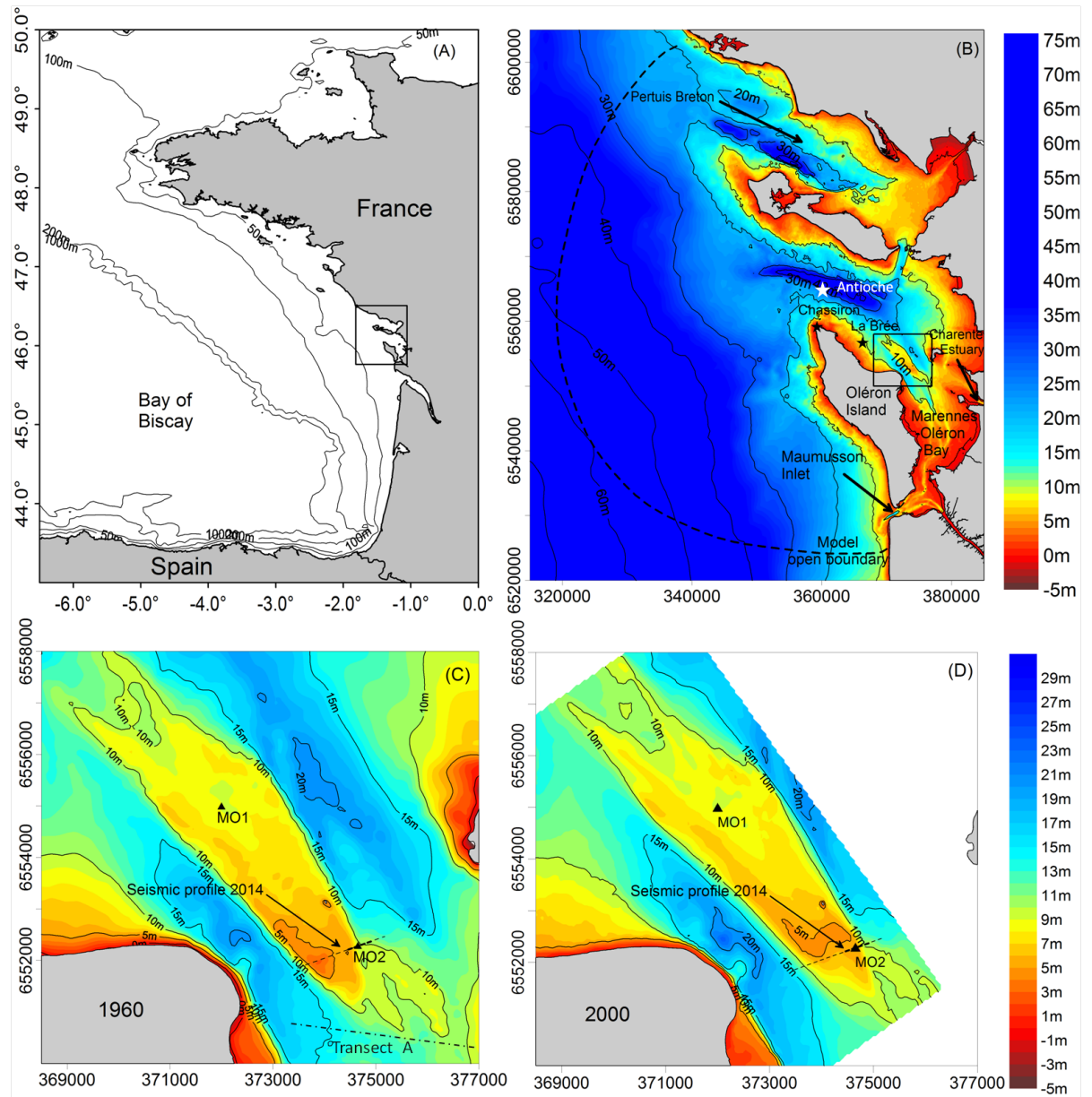

Figure 1: (A) Location of the study area in the Bay of Biscay. (B) Bathymetric map of the study area with respect to mean sea level, with location of the Longe de Boyard sandbank (black square) in the Marennes-Oléron Bay, near the Charente Estuary. (C) and (D) Bathymetry of the sandbank in 1960 and 2000 respectively, with location of the seismic profile realized in 2014, the transect A corresponding to current velocity measurements, the wave station $\mathrm{MO} 1$, and the numerical core station MO2. Coordinates of (B), (C) and (D) are in meters (Lambert-93). 
and erosion of its NE and SW parts (Chaumillon et al., 2002). Seismic reflection exploration of the sediment accretion areas, presented in Chaumillon et al. (2002, 2008), showed inclined reflectors dipping channelward and recording the rhythmic lateral accretion on both sides of the sandbank. Bertin and Chaumillon (2005) explained the observed sediment accretion at the SE part of the sandbank by the crestward convergence of the residual sediment transport. They proposed that this convergence may be due to the crestward deviation of currents in this area, in response to the observed gradient of the free surface elevation above the crest of the bank which is caused by the obliqueness of the crest compared to the axis of the bank.

Since this sandbank presents a tide-dominated morphology and is oriented along the dominant tidal currents direction (i.e. SE-NW axis), one may suggest that tidal processes prevail over wave-induced processes. However, Chaumillon et al. (2008) proposed that wave action could explain the erosion of the seaward part of the bank over the period 1824 to 2000, because of both the relative weakness of tidal currents and the local amplification of wave heights due to convex refraction in this area. Indeed, the strong decrease in wave height from the central part of the bank to its southern end and adjacent channels would induce flows in the direction of wave propagation and adjacent channels.

Nevertheless, these previous studies left us with several open scientific questions of first importance : $(i)$ Can the respective contribution of tide and waves to the sandbank long-term evolution be quantified? (ii) How to explain that lateral accretion occurs, perpendicularly to the main current direction? (iii) Where does the rhythmic behavior of the sediment accretion come from? These questions, which could also be relevant for other wave-influenced sandbanks and sandbanks characterized by lateral accretion, are investigated in the present work. 


\section{The morphodynamic modelling system}

\subsection{Model description}

\subsubsection{Hydrodynamic module}

The core of the modelling system used in this study is the unstructured-grid, parallelized, Semi Eulerian-Lagrangian Finite Element (SELFE) hydrodynamic model of Zhang and Baptista (2008). The main feature of this model is the use of the Eulerian-Lagrangian method to treat the advection in the momentum equations in addition to semi-implicit schemes, which relaxes the numerical stability constraints of the model (e.g. the Courant-Friedrichs-Lewy (CFL) condition can be exceeded). The 2DH configuration of SELFE is used in this study, i.e. the Saint-Venant equations are solved at each hydrodynamic time step to provide the evolution of the surface elevation and the depth-averaged currents over the all computational grid.

\subsubsection{Wave module}

The Wind Wave Model II (WWM-II) of Roland et al. (2012) (third generation, spectral wave model) is coupled to SELFE and simulates gravity waves generation and propagation by solving the wave action equation (WAE) Komen et al., 1996). WWM-II uses a residual distribution scheme (Abgrall, 2006) to solve the geographical advection in the WAE, which also relaxes CFL constraints and allows using large time step without compromising the numerical stability. Regarding the spectral advection (i.e. in the frequency and direction space) in the WAE, it is solved with an Ultimate Quickest scheme (Leonard, 1991).

\subsubsection{Sediment transport and bed evolution module}

The 2DH sediment transport/bottom evolution module SED2D (Dodet, 2013), adapted from MORSYS2D model (Bertin et al. 2009), allows computing the sediment transport using classical semi-empirical formulations based on depth-averaged velocity, water depth, bottom roughness, sediment properties and wave parameters. 
The choice of the sediment transport formulation used to run the morphodynamic simulations was done by comparing measured transport rates from the SANDPIT project (van Rijn et al. 2005) with transport rates predicted by the semi-empirical formulations of van Rijn et al. (2004) [hereinafter TR04], van Rijn (2007a|b) [VR07], Larson et al. (2011) [CL11], and Wu and Lin (2014) [WL14]. Two series of sediment transport measurements were considered : a first one corresponding to shallow conditions and a second one corresponding to deeper conditions (see Tab. 1).

\begin{tabular}{|c|c|c|}
\hline & SANDPIT tests 5 to 9 & SANDPIT tests 19 to 24 \\
\hline$h$ & 3.9 to $5.3 \mathrm{~m}$ & 13.9 to $14.5 \mathrm{~m}$ \\
$H_{s}$ & 0.6 to $1.2 \mathrm{~m}$ & 3.9 to $4 \mathrm{~m}$ \\
$T_{p}$ & 4.4 to $8.1 \mathrm{~s}$ & 9.1 to $10 \mathrm{~s}$ \\
$U_{c}$ & 0.02 to $0.22 \mathrm{~m} / \mathrm{s}$ & 0.13 to $0.52 \mathrm{~m} / \mathrm{s}$ \\
{$[\mathrm{d} 10 ; \mathrm{d} 50 ; \mathrm{d} 90]$} & {$[0.18 ; 0.21 ; 0.30] \mathrm{mm}$} & {$[0.20 ; 0.25 ; 0.39] \mathrm{mm}$} \\
\hline
\end{tabular}

TABLE 1: Experimental conditions for the two SANDPIT datasets. $h$ is the water depth, $H_{s}$ is the significant wave height, $T_{p}$ is the wave peak period, $U_{c}$ is the depth-averaged current velocity, and d10, d50 and d90 are the grain diameters for which $10 \%, 50 \%$ and $90 \%$ of the grains by mass is finer, respectively.

Only the suspended-load was measured in the scope of the SANDPIT project but, since the suspended-load transport $\left(q_{s}\right)$ is the main contribution of the total transport in this type of coastal conditions, these datasets allowed us to perform relevant comparisons between the four transport formulations. The scatter plots related to these comparisons are shown on Fig. 2. It can be seen on this figure that $q_{s}$ is globally better predicted with the formulations of TR04 and WL14 than with VR07 and CL11 formulations. The scatter index (SI) values are indeed much higher for VR07 and CL11 formulations, because of the significant overestimation of $q_{s}$ for the deeper conditions (blue circles) which contributes more to increase the SI than underestimating $q_{s}$. Moreover, although the formulations of TR04 and WL14 perform well in terms of SI score 
(both SI equal about 60\%), the TR04 formulation tends more to overestimate $q_{s}$ than the WL14 formulation. Morphodynamic simulations were run with these four formulations and, consistently with the previous comparisons of predicted transport rates, the bathymetry appeared to degenerate significantly with the TR04, VR07 and CL11 formulations as attested by strongly negative Brier Skill Scores (as defined in Fortunato et al. (2014)) ranging from -7.51 to -1.08 (not shown). Therefore, we chose to use only the WL14 formulation thereafter.

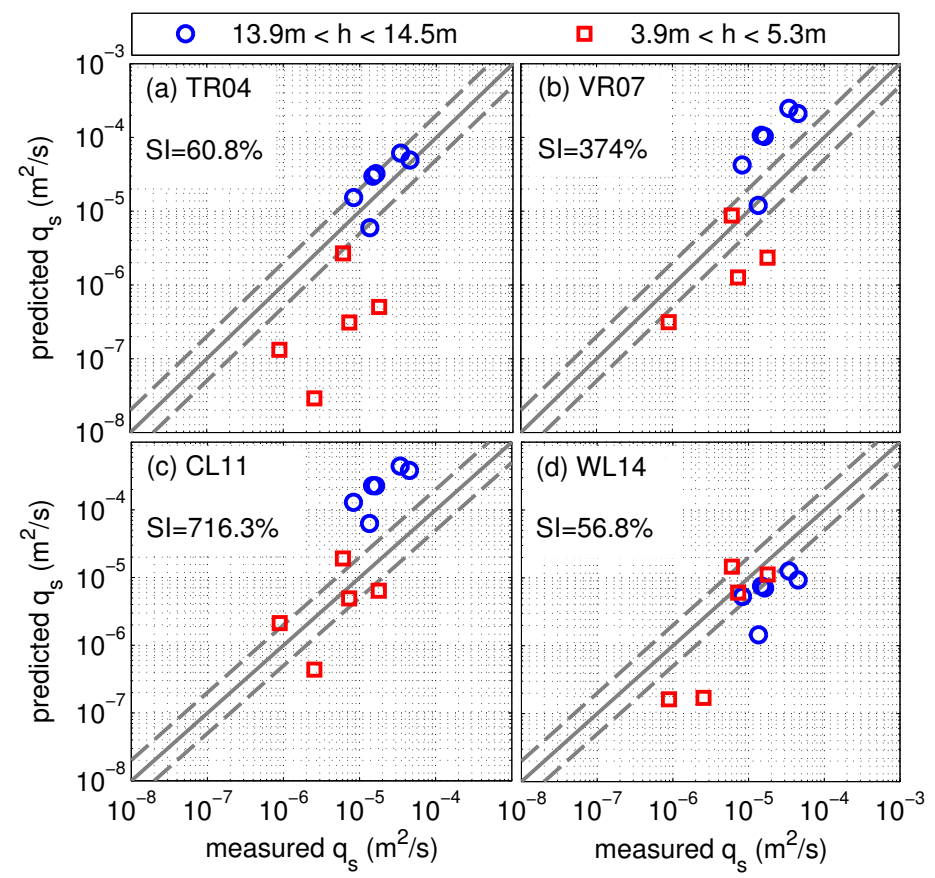

Figure 2: Comparison between suspended-load transport rates measured in the scope of the SANDPIT project with predicted values given by the formulations of : (a) van Rijn et al. (2004) [TR04], (b) van Rijn (2007a b) [VR07], (c) Larson et al. (2011) [CL11], and (d) Wu and Lin (2014) [WL14].

The formulation of WL14 was developed to estimate the transport of a multisized sediment under the combined action of (non-breaking) waves and currents. For each grain size class $i$, the bed-load transport $\boldsymbol{q}_{\boldsymbol{b}, \boldsymbol{i}}=\left(q_{b, i, x}, q_{b, i, y}\right)$ is compu- 
ted as :

$$
q_{b, i}=q_{b, i, o n}+q_{b, i, o f f}
$$

where $\boldsymbol{q}_{\boldsymbol{b}, \boldsymbol{i}, \boldsymbol{o n}}$ and $\boldsymbol{q}_{\boldsymbol{b}, \boldsymbol{i}, \boldsymbol{o f f}}$ are respectively the onshore and offshore part of the bed-load transport during the wave period $T_{w}$. The respective direction of $\boldsymbol{q}_{\boldsymbol{b}, \boldsymbol{i}, \boldsymbol{o n}}$ and $\boldsymbol{q}_{\boldsymbol{b}, \boldsymbol{i}, \boldsymbol{o f f} \boldsymbol{f}}$ is computed according to the sketch of Wu and Lin (2014), and the norm of these two vectors is computed as :

$$
q_{b, i, \text { on }(\text { off })}=5.3 .10^{-3} f_{i} \sqrt{(s-1) g d_{i}^{3}} \frac{T_{\text {on }(\text { off })}}{T_{w}}\left(\frac{\tau_{b, o n(o f f)}^{\prime}}{\tau_{c r, i}}-1\right)^{2.2}
$$

where $f_{i}$ is the local available fraction of sediment class $i, s$ is the ratio between sediment density $\rho_{s}$ and water density $\rho, d_{i}$ is the grain size diameter for sediment class $i$, and $T_{\text {on (off) }}$ is the onshore (offshore) half wave period.

The onshore and offshore grain shear stresses are computed as :

$$
\left\{\begin{array}{l}
\tau_{b, o n}^{\prime}=\frac{1}{2} \rho f_{c w}^{\prime}\left(U_{c}^{2}+U_{w m, o n}^{2}+2 U_{c} U_{w m, o n} \cos (\phi)\right) \\
\tau_{b, o f f}^{\prime}=\frac{1}{2} \rho f_{c w}^{\prime}\left(U_{c}^{2}+U_{w m, o f f}^{2}+2 U_{c} U_{w m, o f f} \cos (\pi-\phi)\right)
\end{array}\right.
$$

where $f_{c w}^{\prime}$ is the grain friction coefficient for combined current and waves, $U_{c}$ is the depth-averaged current velocity, $U_{w m, o n(o f f)}$ is the root-mean-square value of the wave orbital velocity over $T_{\text {on }(o f f)}$, and $\phi$ is the angle between current and wave directions.

$\tau_{c r, i}$ is the critical shear stress for the incipient motion of sediment class $i$, which is computed as :

$$
\tau_{c r, i}=g\left(\rho_{s}-\rho\right) d_{i} \theta_{c r}\left(\frac{p_{e, i}}{p_{h, i}}\right)^{-0.6}
$$

where $\theta_{c r}=0.03$ is the critical Shields number for incipient motion of the median diameter (d50) of the bed sediment which was calibrated by Wu and Lin (2014) using laboratory and field data. $p_{e, i}$ and $p_{h, i}$ are respectively the exposed and hidden probabilities of grain size $d_{i}$ in the bed material, computed following $\mathrm{Wu}$ et al. (2000) :

$$
p_{e, i}=\sum_{j=1}^{N} f_{j} \frac{d_{i}}{d_{i}+d_{j}} \text { and } p_{h, i}=\sum_{j=1}^{N} f_{j} \frac{d_{j}}{d_{i}+d_{j}}
$$


where $N$ is the number of grain-size classes, and $f_{j}$ is the fraction of sediment size class $j$ in the bed material.

In the absence of waves, the norm of the bed-load transport is computed as :

$$
q_{b, i}=5.3 .10^{-3} f_{i} \sqrt{(s-1) g d_{i}^{3}}\left(\frac{\tau_{b, c}^{\prime}}{\tau_{c r, i}}-1\right)^{2.2}
$$

where $\tau_{b, c}^{\prime}$ is the grain shear stress due to currents which is computed as :

$$
\tau_{b, c}^{\prime}=\frac{1}{2} \rho f_{c}^{\prime} U_{c}^{2}
$$

where $f_{c}^{\prime}$ is the grain friction coefficient due to currents. In this case, the direction of $\boldsymbol{q}_{\boldsymbol{b}, \boldsymbol{i}}$ is the current direction.

The suspended-load transport $\boldsymbol{q}_{\boldsymbol{s}, i}$ is assumed to be along the current direction, and its norm is computed as :

$$
q_{s, i}=2.62 .10^{-5} f_{i} \sqrt{(s-1) g d_{i}^{3}}\left[\left(\frac{\tau_{b}}{\tau_{c r, i}}-1\right) \frac{U_{c}}{w_{s, i}}\right]^{1.74}
$$

where $w_{s, i}$ is the settling velocity of sediment class $i$. The total bed shear stress $\tau_{b}$ is computed as :

$$
\tau_{b}=\sqrt{\tau_{b, c}^{2}+\tau_{b, w m}^{2}+2 \tau_{b, c} \tau_{b, w m} \cos (\phi)}
$$

where $\tau_{b, c}=\frac{1}{2} \rho f_{c} U_{c}^{2}$ and $\tau_{b, w m}=\frac{1}{4} \rho f_{w} U_{w}^{2}$ are the bed shear stresses due to current only and due to waves only, with $f_{c}$ and $f_{w}$ being the related friction coefficients, and $U_{w}$ being the amplitude of the wave orbital velocity near the bed.

Finally, the bed evolution is computed at each grid node in SED2D by solving the Exner equation :

$$
\frac{\partial z_{b}}{\partial t}+\frac{1}{1-\lambda} \nabla_{\boldsymbol{x}} \cdot \boldsymbol{q}=0
$$

where $\boldsymbol{x}=(x, y), z_{b}(x, t)$ is the bed level elevation (positive upwards), $\lambda$ is the sediment porosity, and $\boldsymbol{q}=\left(q_{x}, q_{y}\right)=\sum_{i=1}^{N}\left(\boldsymbol{q}_{\boldsymbol{b}, \boldsymbol{i}}+\boldsymbol{q}_{\boldsymbol{s}, \boldsymbol{i}}\right)$ is the depth-integrated sediment total transport rate (in $\mathrm{m}^{3} / \mathrm{m} / \mathrm{s}$ ) computed at element centres. The finite volume WENO-based method of Guérin et al. (2016) is used to solve this equation while preventing the development of numerical oscillations. 


\subsection{Model implementation}

\subsubsection{Computational grid and external forcings}

The unstructured computational grid used in this study extends from the south of the Maumusson inlet to the north of the Pertuis Breton, and the water depth reaches about $60 \mathrm{~m}$ at the offshore boundary (Fig. 1 (B)). Its resolution ranges from $2.5 \mathrm{~km}$ offshore to $100 \mathrm{~m}$ in the sandbank area. The wave forcing is obtained from the hindcast of Bertin et al. (2013) which used the spectral wave model WaveWatch-III (Tolman and others, 2009) forced with NCEP reanalysis wind fields (Kalnay et al. 1996).

A morphological factor of 10 was used in order to speed up the simulation, meaning that the morphological changes computed during the morphological time step (i.e. the time between two bathymetric updates) was multiplied by 10 while the total simulation time was 4 years instead of 40 . To be consistent with the use of a morphological factor, a representative tidal forcing was considered as proposed in the work of Latteux (1995). By taking as a reference the residual sediment transport computed over the sandbank area for a one-year simulation with realistic tidal and wave forcings, the representative tide was adjusted such as the corresponding representative simulation gives a residual sediment transport close to the reference result over the whole sandbank area. The representative tide selected is composed of the quarter-diurnal constituent (M4) and a M2* constituent which has the same period than the semi-diurnal constituent M2 $\left(T_{M 2}=12.42 \mathrm{~h}\right)$ but an amplitude $30 \%$ higher than the M2 amplitude. Consequently to the use of a morphological factor, the time corresponding to the realistic wave forcing was squeezed (i.e. 10 minutes became 1 minute).

As explained in Zhang and Baptista (2008), the Eulerian-Lagrangian method employed in SELFE constrains the use of relatively large time steps (i.e. for which the CFL number is close to 1 or even superior to 1) for better accuracy. In our case, a stable configuration was obtained with a hydrodynamic time step of $120 \mathrm{~s}$, giving a CFL number less than 2 (maximum current velocity in 
the fine resolution $(100 \mathrm{~m})$ area is about $1.5 \mathrm{~m} / \mathrm{s}$ leading to a CFL number of $\left.1.5^{*} 120 / 100=1.8\right)$. The morphological time step was set to the period of the main tidal constituent $\left(T_{M 2}=12.42 \mathrm{~h}\right)$ in order to speed up the simulation, while remaining sufficiently small compared to the relatively slow morphological changes.

Since both the grid resolution and the modelling system were not configured to handle the diverse physical processes taking place all over the computational grid (e.g. the high fraction of cohesive sediments in the channels along the sandbank sides and in the southern part of the bay, and the wave induced dynamics at the surrounding shoreline which would require a finer grid resolution), a morphological ramp was used in order to update the bathymetry only in the sandbank area and to avoid unrealistic morphological changes elsewhere. To verify that this ramp doesn't impact the morphodynamic hindcast, we performed a simulation where the surrounding bathymetry of 1960 was replaced by the one of 2000. This simulation didn't yield significantly different morphological changes of the sandbank, which would suggest that the use of such a ramp is a reasonable simplification. A negligible impact on the morphodynamic hindcast was also obtained concerning the sea level rise that took place between 1960 to 2000 (about $+8.4 \mathrm{~cm}$ according to Gouriou et al. (2013)).

\subsubsection{The multi-class and multi-layer (MCML) method}

Considering a multiple-sized sediment led us to implement a MCML method into our sediment transport and bed evolution module SED2D. The method proposed by Reniers et al. (2013) was used in this study, allowing us to obtain the temporal evolution of the sediment composition 3D distribution (grain-size and sorting). The initial configuration consisted of 400 layers of $1 \mathrm{~cm}$ thickness, along with three grain-size classes of $0.1 \mathrm{~mm}, 0.2 \mathrm{~mm}$, and $0.35 \mathrm{~mm}$ diameter and respective fractions of $10 \%, 80 \%$, and $10 \%$ according to the vibrocore data presented in Chaumillon et al. (2008). At every time step, the median diameter was computed in each layer using a geometric mean (initial value of nearly $0.2 \mathrm{~mm})$. 


\section{Modelling results}

\subsection{Water levels}

Bottom pressure measurements were performed with a Nortek Vector current meter equipped with a pressure sensor at a station located at the NW side of the sandbank (see station La Brée on Fig. 1(B)) from November to December 2009, and with a Nortek AWAC current meter at a second station located in the "Pertuis d'Antioche" (see Antioche station on Fig. 1(B)) from January to February 2010. The comparison between measured and simulated water levels at these two stations are shown on Fig. 3 (a) and Fig. 4 (a). Regarding these two stations the related root-mean-square error (RMSE) ranges between 0.14 and $0.21 \mathrm{~m}$ for the total water depth (i.e. sum of tide and surge), which yields an error of about 4 to $5 \%$ when normalized by the mean tidal range. Such result is satisfactory when compared to previous modelling studies on this area (Bertin et al. 2012, Toublanc et al., 2015).

\subsection{Waves}

The computation of wave parameters from the bottom pressure measurements recorded at La Brée station was done by first correcting these measurements from sea level pressure measured at the nearby station of Chassiron. A bottom pressure spectra was then computed using Fast Fourier Transform over 20 min bursts, and this pressure spectra was converted into elevation spectra using linear wave theory. The significant wave height $H_{m 0}$ was computed as $4 \sqrt{m_{0}}$ where $m_{0}$ is the $0^{\text {th }}$ moment of the elevation spectra, and the peak period $T_{p}$ as the period where the maximum energy was found in the range [0.33-0.04Hz]. Simulated $H_{m 0}$ and $T_{p}$ without bathymetric update (i.e. only SELFE-WWM-II, with the bathymetry of 2000) were compared against the values obtained from measurements (Fig. 3 (b)-(c)). RMSE and normalized RMSE are respectively $0.21 \mathrm{~m}$ and $26.6 \%$ for $H_{s}$, and $1.27 \mathrm{~s}$ and $9.6 \%$ for $T_{p}$, which are reasonably good results given the very coarse spatio-temporal resolution of the atmospheric forcing (about $1.9^{\circ}$ in latitude and longitude, and $6 \mathrm{~h}$ in time). 
Regarding the Antioche station, the instrument was not calibrated to extract wave parameters.



Figure 3: Comparison of measurements and simulated results for water level, significant wave height $(\mathrm{Hs})$, and peak period $(\mathrm{Tp})$ at La Brée station, from November $18^{\text {th }}$ to December $12^{\text {th }}$ 2009.

\subsection{Currents}

Vertical profiles of current velocity were measured at the Antioche station (see Fig. 1 (B)) from January to February 2010, and were also measured several times along a same transect located at the south end of the sandbank (see transect A on Fig. 1 (C)) to cover a tidal cycle on November $6^{\text {th }}$ of 2002.

These two datasets were first used to estimate the local Manning's number $(n)$ which is needed as an input parameter in our hydrodynamic module to handle the bottom friction. According to the method of Soulsby (1997), a linear regression was performed on each scatter plot $\{U(z) ; \ln (z)\}$, where $z$ is the vertical distance from the bottom and $U(z)$ is the related horizontal fluid velocity. This linear regression allowed us to compute the friction velocity $u_{*}$ and the bed roughness length $z_{0}$ by using the expression $U(z)=A \ln (z)+B$ where 
$A=u_{*} / K$ and $B=-A \ln \left(z_{0}\right), K$ being the von Karman's constant. The drag coefficient was then computed as $C_{d}=\left[K /\left(1+\ln \left(z_{0} / h\right)\right)\right]^{2}$, where $h$ is the water depth, and the Manning's number was finally computed as $n=\sqrt{C_{d} h^{1 / 3} / g}$. Since this method was developed for current-only conditions, periods of calm weather (i.e. weak waves and wind) were favored and velocity measurements in the sub-surface layer were removed for this computation. Though this analysis was not sufficient to build a spatial distribution of the Manning's number over the all computational grid, it allowed us to estimate a mean value of the Manning's number which was then used in all our numerical simulations. This value appeared equal to 0.03 and was used for all our numerical simulations.

The depth-averaged current velocity $\left(U_{c}\right)$ obtained from measurements was compared with the simulated one at Antioche station (see Fig. 4(b)) and along the transect A (not shown). While the model underestimates the current velocity at Antioche station (mean bias of $-0.06 \mathrm{~m} / \mathrm{s}$ ), this trend disappears for the results along the transect A (mean bias ranging between about -0.05 and $0.05 \mathrm{~m} / \mathrm{s}$ ). The related normalized root-mean-square error (NRMSE) at the Antioche station is about $22 \%$, while for the transect $\mathrm{A}$ it reaches about $15 \%$ when $U_{c}>0.5 \mathrm{~m} / \mathrm{s}$ (transects made during mid-tide) and about 30 to $40 \%$ when

$U_{c}<0.5 \mathrm{~m} / \mathrm{s}$ (transects made close to high tide and low tide). Regarding the current direction, the bias between simulated and measured values at the Antioche station is almost constant (about $20^{\circ}$, see Fig. 4 (c)), but it becomes more variable along the transect $\mathrm{A}$ (ranging between about $-15^{\circ}$ and $15^{\circ}$ ).

\subsection{Morphological evolution}

Bathymetric survey of the bank was done in 1960 and 2000 (Fig. 1 (C) and (D)) with bathymetric uncertainty of $0.35 \mathrm{~m}$ (Bertin et al., 2005), allowing us to study the 40-year morphological evolution of this sandbank. The measured morphological evolution (Fig. 5(a)) is characterized by lateral sediment accretion of the SE and NW flanks of the bank, and sediment erosion mainly at the south of the bank and along its SW flank. Considering that both tide and wave-related processes may explain the observed evolution of the sandbank, two morphody- 

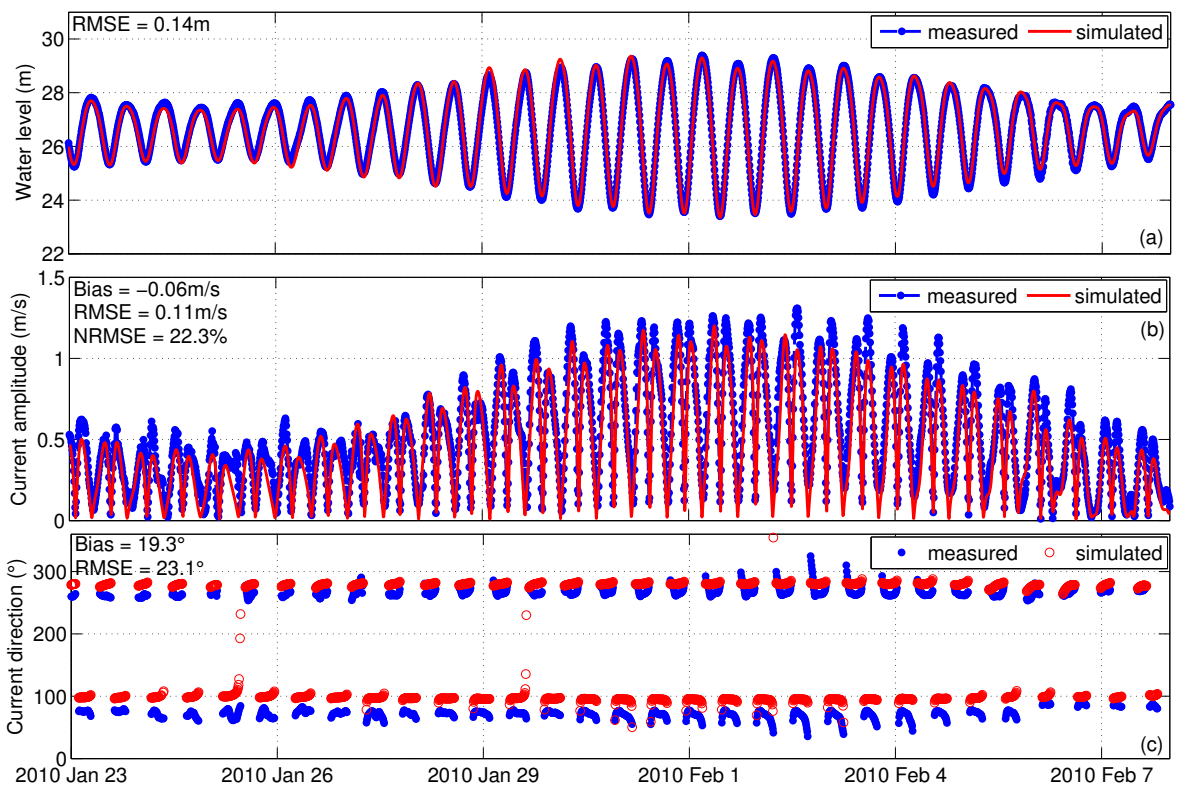

Figure 4: Comparison of measurements and simulated results for water level, and depthaveraged current amplitude and direction at the Antioche station, from January $23^{\text {rd }}$ to February $8^{\text {th }} 2010$. 
namic simulations were considered, the first including tidal forcing only (Fig. 5 (b)), and the second including tidal and waves forcing (Fig. 5 (c)). While only the top of the sandbank did evolve in the case of the tide-only forcing, considering a tidal and waves forcing clearly improved the morphodynamic hindcast with qualitative agreement obtained over almost the all sandbank area except the SW flank of the bank. It is interesting to note that the corresponding Brier Skill Score (BSS) was found to be lower in the latter case (BSS of -0.18) than in the case of the tide-only forcing (BSS of about 0.01). Having a better BSS in a simulation where almost no morphological change takes place compared to a simulation which captured several of the main morphological changes questions the relevance of this metric, as already pointed out by Bosboom and Reniers (2014).

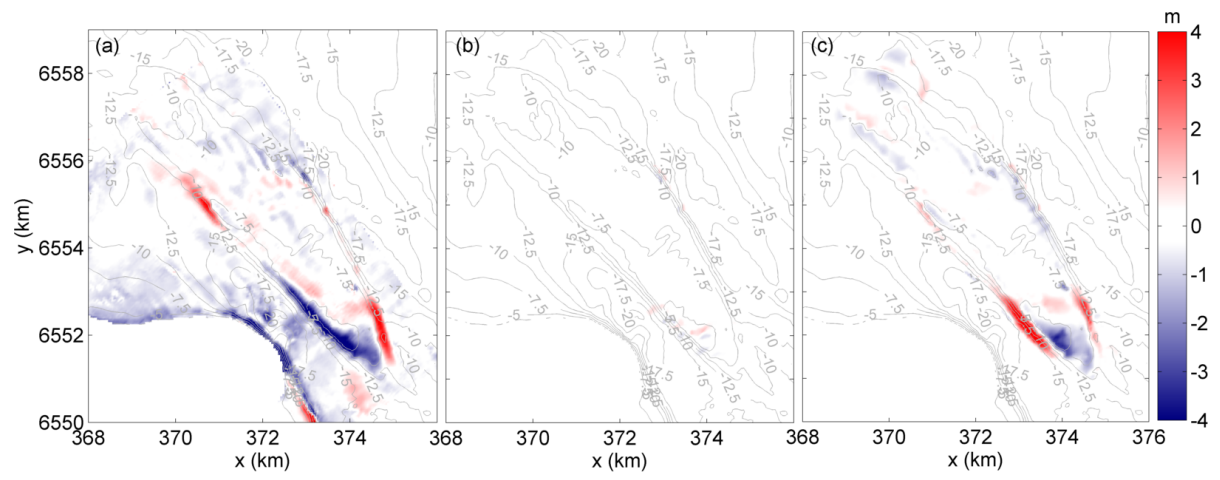

Figure 5: Differential bathymetric maps for the 40-year period (1960 to 2000). (a) Measured map; (b) Simulated map with tidal forcing only; (c) Simulated map with tidal and waves forcing.

\section{Discussion}

\subsection{Limitations of our modelling approach}

The comparison between model results and the available field data revealed firstly that water levels, wave parameters and depth-averaged currents are reproduced with an accuracy corresponding to the state of the art for such an 
estuarine environment. However, the 2DH configuration of our modelling system is a first limitation since 3D circulations may lead to a possible veering of the currents along the vertical direction, thus influencing the sediment transport. Then, more current velocity measurements would allow to enhance the parametrization of the bottom friction, for instance it would be relevant to use a realistic spatial distribution of the Manning's number over the all computational grid. Regarding the sediment composition, though the integration of a multiple-sized sediment through the MCML method is an important improvement compared to a single-sized sediment, simulations would still benefit from a spatially-varying d50 initialization. Sediment availability could also be improved since the assumption of an unlimited quantity of sand over the full computational grid is considered in our study. An additional simplification is the use of a morphological factor, which prevents us to analyze the impact of the tidal range on the morphological evolution of the bank. Finally, the model misses the role of cohesive sediments, mainly present in the channels adjacent to the sandbank and further south between the sandbank and the Charente Estuary (Fig. 1). Cohesive sediments can significantly impact the hydrodynamics, for instance the bottom shear stress may decrease compared to the case of non-cohesive sediment. The sediment transport can also be modified in several ways due to the presence of mud, including the process of dynamic bed armouring, where the resuspension of a sediment mixture (sand+mud) is limited or prevented by the present mud fraction (Le Hir et al., 2011).

Despite these limitations, simulating the evolution of a sandbank subjected to tides and waves over 40 years remains very challenging and we propose that our modelling results still provide some relevant leads about the processes that control the long-term evolution of this wide estuary mouth sandbank.

\subsection{Driving mechanisms for the long-term evolution of the sandbank}

The first result of the present study is the significant improvement of the modelled morphological evolution obtained when a realistic wave forcing was added to the tidal forcing. This result confirms the assumption of Chaumillon 
et al. (2008) according to which waves might have a significant impact on this sandbank evolution, and more generally on estuary mouth sandbanks, though this type of bank can be characterized by an overall tide-dominated morphology and classified as a tidal sandbank. To further investigate the impact of waves on sediment transport, residual sediment transport maps of the southern part of the bank were computed (Fig. 6]: vectors), for tidal forcing only and for tide and energetic offshore wave conditions $\left(H_{s}=4 \mathrm{~m}, T_{p}=11 \mathrm{~s}, \operatorname{Dir}_{p}=N 290^{\circ}\right.$, such wave conditions leading to $H_{s}$ reaching about $1.3 \mathrm{~m}$ in the sandbank area). Since the bed evolution is proportional to the divergence of sediment transport, computing the divergence of the residual sediment transport shows where erosion and accretion occur over a tidal cycle (Fig. 6: colors). Indeed, at the southern tip of the bank, the decreasing water depths towards the bank crest induces an increase of the residual sediment transport (i.e. minus their divergence is negative; blue color on Fig. 6), and therefore an erosion of the corresponding area. Whereas along the SE flank of the bank, both the convergence of the residual transport and the increasing water depths (thereby decreasing sediment transport) towards the channel induce an accretion of the area (i.e. minus the divergence of residual transport is positive ; red color on Fig. 6. Interestingly, the erosion and accretion patterns computed over a single tidal cycle match the long term evolution of the bank, which would suggest that, in this area, this long term evolution is well explained by the sediment transport in the presence of energetic waves and averaged over a tidal cycle.

The sediment transport direction appeared also affected by wave action, especially along the SE flank of the sandbank where the main accretion is observed. The channelward component of residual sediment transport in this area appeared clearly visible when waves were added, explaining the lateral sediment accretion observed along this flank. Therefore, the fact that sediment deposition occurred in a direction normal to the dominant tidal currents direction (i.e. the sandbank main axis), which could be thought rather counterintuitive, is explained by the presence of waves. This result is of great importance as lateral accretion of sandbanks is widely documented (e.g. Houbolt, 1968; Harris, 1988 , 


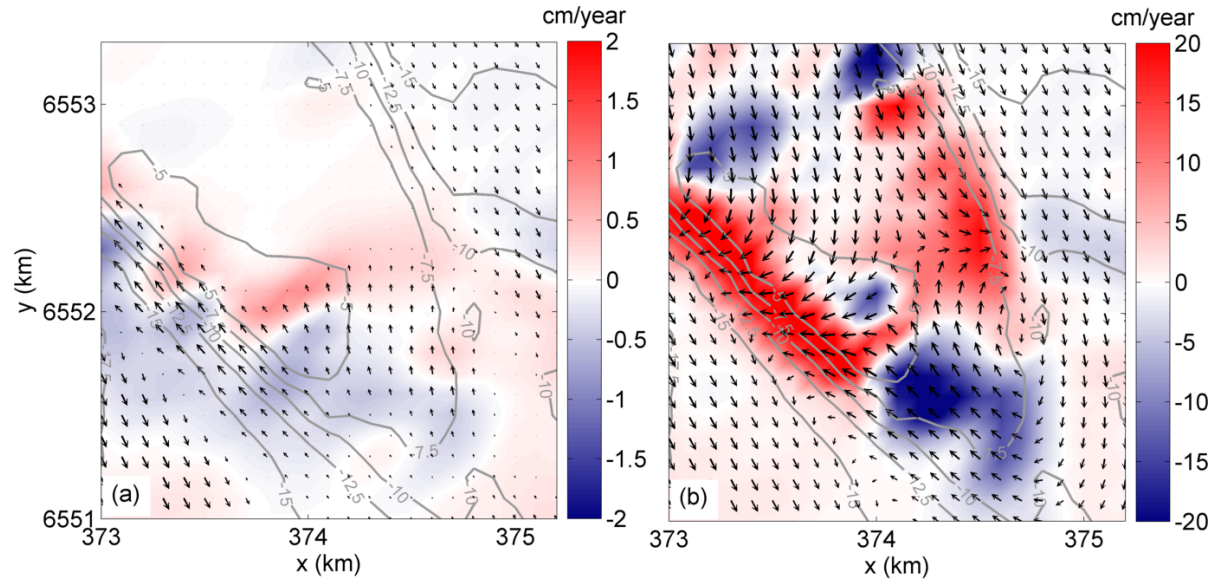

FiguRE 6: Residual sediment transport (arrows) with related accretion and erosion areas (colors) (computed as minus the divergence of the residual transport), for a tidal cycle and in the south area of the bank : (a) tide-only forcing, (b) tide and waves forcing (offshore wave parameters : $\left.H_{s}=4 \mathrm{~m}, T_{p}=11 \mathrm{~s}, \operatorname{Dir}_{p}=\mathrm{N} 290^{\circ}\right)$.

Berné et al., 1994; Dalrymple and Rhodes, 1995, Olariu et al., 2012, Chaumillon et al. 2013).

These large differences of residual transport patterns between the tide-only and the tide and waves cases can be explained by comparing the instantaneous sediment transport for current alone and for combined current and wave over a wave period (Fig. 7). Though adding the wave orbital velocity to the current velocity does not modify the mean total velocity compared to the case with current alone (i.e. in both cases the mean total velocity equals to the current velocity), the corresponding mean sediment transport for current and wave is about one order of magnitude higher than the one for current alone. This difference is due to the non-linear dependence between the sediment transport and the fluid velocity (i.e. the sum of the current velocity and the wave orbital velocity), and explains the increase of sediment transport rates shown on Fig. 6.

\subsection{Origin of the rhythmic accretion}

Since the wave control on the sandbank evolution was found to be essential, the next step of this study was to analyze how the strong seasonal variation of 

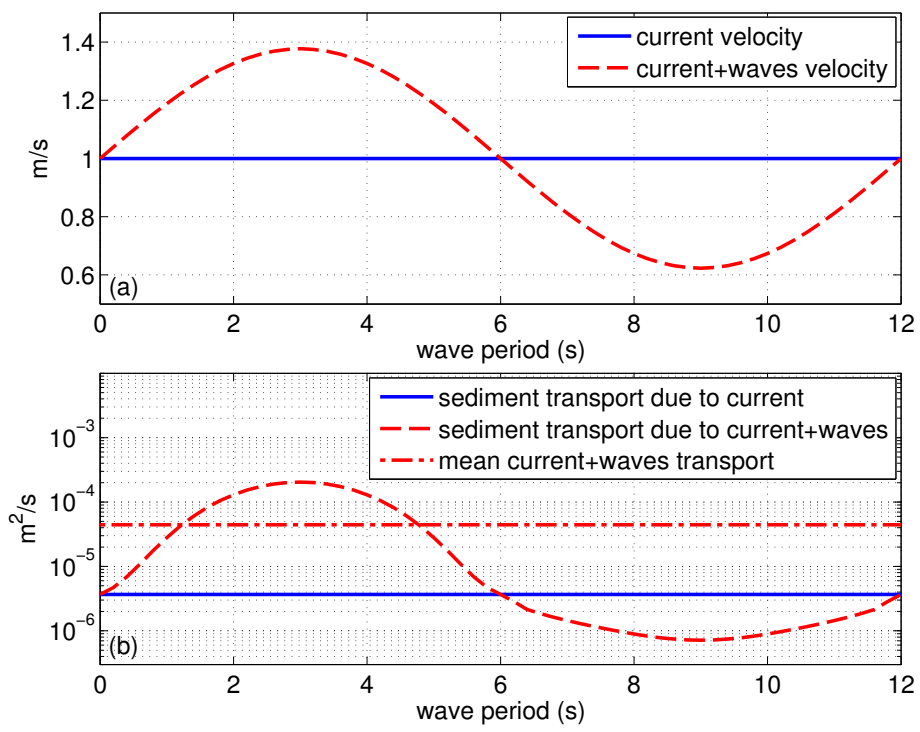

Figure 7: (a) Instantaneous fluid velocities for current alone $(1 \mathrm{~m} / \mathrm{s})$, and for current with additional sinusoidal wave (wave height of $0.5 \mathrm{~m}$, period of $12 \mathrm{~s}$, wave direction equals to the current direction, and water depth of $4 \mathrm{~m}$ ). (b) Related instantaneous sediment transport (same grain-size parametrization than in the present modelling study), with mean transport for the combined current and wave case. 
the wave climate in the NE Atlantic Ocean (Dodet et al., 2010) may affect the morphological evolution rate. Fig. 8 (a) compares the significant wave height variation $H_{s}(t)$ at a station located on the central part of the sandbank (see station MO1 on Fig. 1 (C)) with the absolute rate of change of the bed level in the SE accretion area (see station MO2 on Fig. 1(C)). A correlation coefficient of 0.37 with a $95 \%$ confidence interval is obtained when considering monthly averaged signals over the 40-year period, which is consistent with the hypothesis of a significant wave control on the sandbank morphodynamic.

Moreover, the integration of a MCML approach into SED2D enabled us to study the impact of the wave climate variation on the sediment composition. Fig. 8 (b) compares $H_{s}(t)$ at station MO1 with the absolute rate of change of the d50 computed in the surface layer at station MO2. A correlation coefficient of 0.32 with a $95 \%$ confidence interval is obtained when considering monthly averaged signals over the 40-year period, which reflects the tendency of the grain size to vary preferentially during periods of energetic waves (i.e. winter periods).
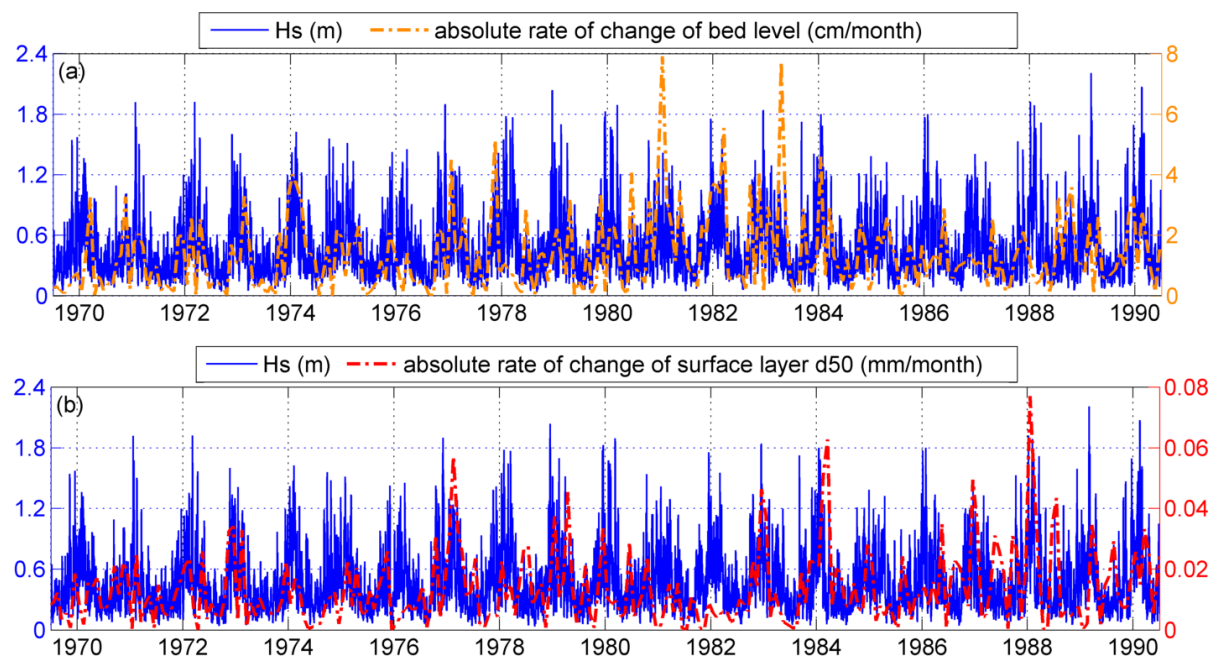

Figure 8: Temporal variation of significant wave height (Hs) at station MO1 (see Fig. 1 (C)) with absolute rate of change of (a) bed level and (b) d50 of the surface layer at station MO2, between 1970 and 1990. 
By considering a "numerical core" in the SE accretion area (see Fig. 9), we can also analyze how the vertical variation of the sediment granulometry is recorded through time. Firstly, it can be observed that the largest accretion occurs during winter periods (more dark blue bars than yellow or light blue bars), i.e. periods of energetic waves, which is in agreement with the important wave control on the morphological evolution previously highlighted (Fig. 8(a)). Secondly, a seasonal variation of the median grain size is obtained, which is also in agreement with the previous results shown on Fig. 8 (b). It is finally interesting to see that winter periods can be related to peaks of relatively coarse sediment (like the winters of 1983-84 and 1984-85 for instance), while they can also be related to peaks of relatively fine sediment (like the winter of 1987-88 for instance). This complex behavior reflects probably the complex variation, both in time and space, of the local grain size fractions.

A seismic reflection survey of the sandbank realized in July 2014 allowed us to compare seismic and modelled stratigraphy in the SE accretion area. Inclined and channelward dipping reflectors are observed on the seismic profile (Fig. 10), showing contrast of acoustic impedance that can be interpreted as rhythmic lateral migration of the sandbank. Interestingly, the number of reflectors observed on this seismic profile between the bathymetric profiles of year 2000 and 2014 is of the order of 15 , which corresponds to approximately one reflector per year. The number of reflectors between 1960 and 2000 is less easy to count, but a reflector frequency ranging between 0.75 and 1.25 reflector per year is observed on the same figure. Seismic reflectors observed in this area were already correlated with vertical grain size variations (Billeaud et al. 2005). Therefore, the vertical distribution of the d50 obtained numerically (Fig. 9 reinforces this assertion, since this variation is characterized by a seasonal cycle (i.e. a frequency of one reflector per year). This result also confirms the previous interpretations of Berné et al. (1994) and Chaumillon et al. (2008) who proposed that reflectors recording the lateral accretion of sandbanks could result from wave action. Note that such numerical investigations would not have been possible if an input reduction technique was considered for the wave forcing (e.g. a randomly 


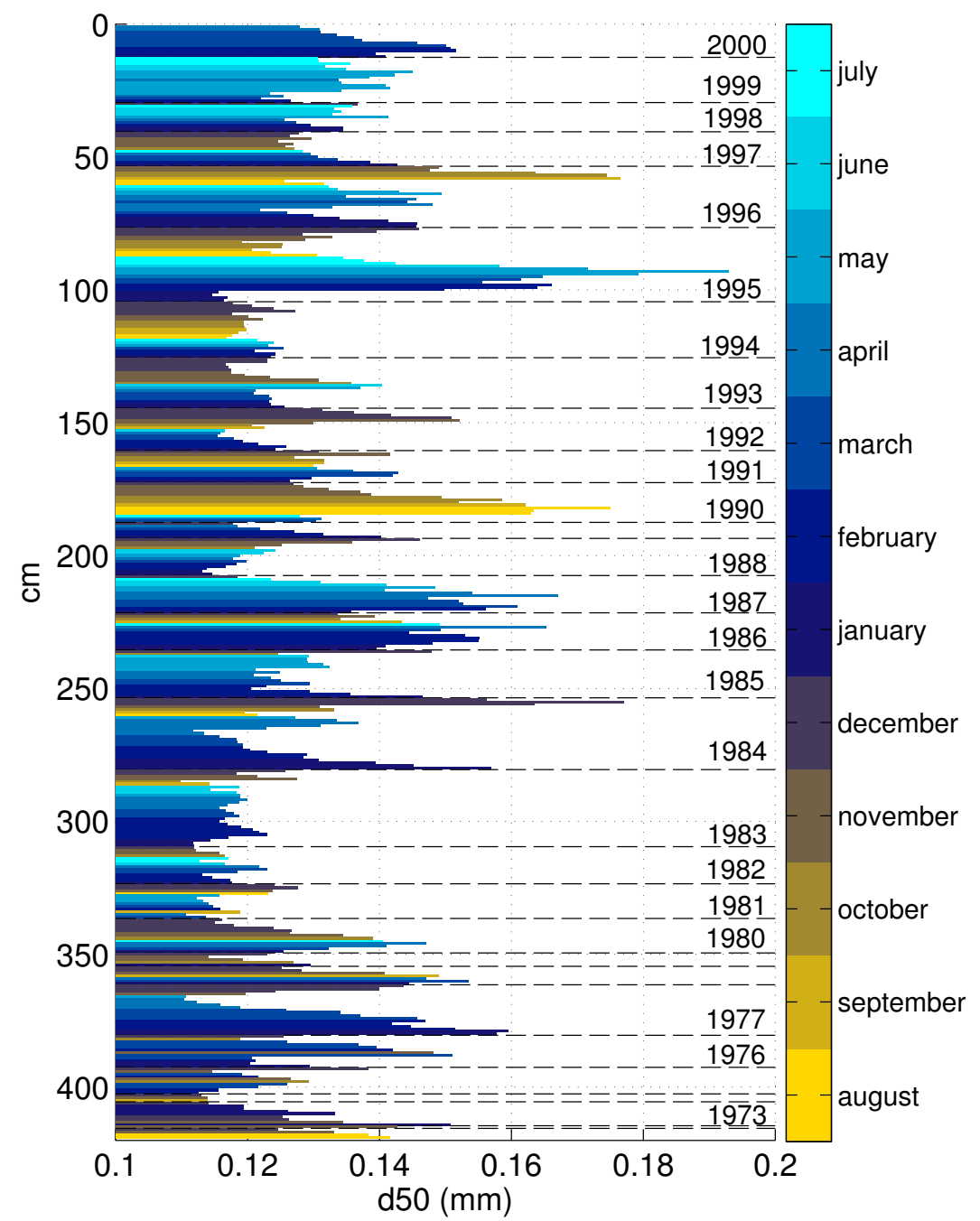

Figure 9: Numerical core computed in the SE accretion area at the station MO2 (see Fig. 1 (C)) at the end of the simulation. Vertical variation of the median grain diameter corresponding to year 1972 to 2000 are visible. 
sequenced wave climate, as proposed by Walstra et al. (2013)).

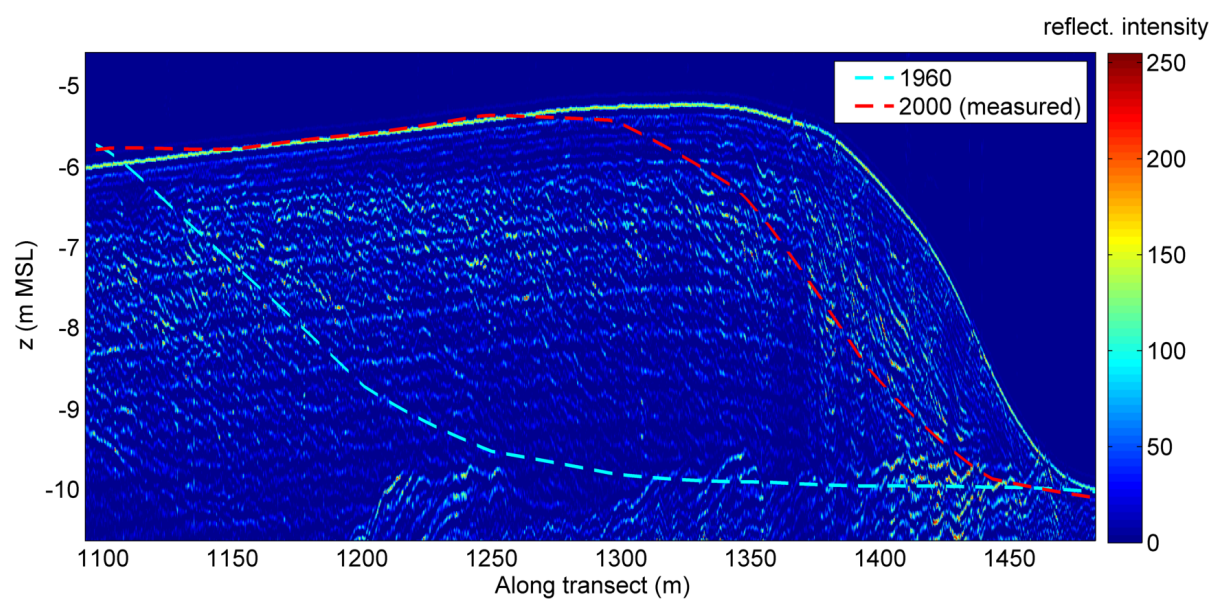

Figure 10: Seismic profile in the SE accretion area of the sandbank recorded in July 2014 (see Fig. 1(C)), with superposed 1960 and 2000 bathymetric profiles.

\section{Conclusions}

This process-based modelling study highlighted the strong control of waves on the morphological evolution of a wide estuary mouth sandbank, in spite of its global tide-dominated morphology. The divergence of residual sediment transport over one single tidal cycle and in the presence of energetic waves is consistent with the long-term evolution of the bank, which would suggest that this long-term evolution is well explained by the short-term sediment dynamics during energetic periods. It was shown that these energetic waves, mostly occuring during winter periods, induce an important channelward sediment transport in the main accretion area of the bank, which explains the observed lateral accretion. This rhythmic accretion consists of an alternation of thicker sand layers, emplaced during periods of higher wave energy, and thinner sand layers, emplaced during periods of lower wave energy. A seasonal cycle is also found in both the temporal and vertical variation of the sediment granulometry. Based on the fact that seismic reflectors can be related to grain size variations, a frequency 
of about one reflector per year was obtained with the model, which appears supported by recent seismic data. These results may be considered for other estuary mouth sandbanks and other sandbanks that are potentially affected by waves.

\section{Acknowledgements}

The AWAC data collected at the Antioche station and the Vector data collected at La Brée station were provided by the French Oceanographic and Hydrographic Institute (SHOM), acquired during the projects MOUTON (funded by DGA PEA 012401) and EPIGRAM (funded by LEFE/IDAO and ANR, agreement ANR-08-BLAN-0330-01).

\section{References}

Abgrall, R., 2006. Residual distribution schemes : Current status and future trends. Computers \& Fluids 35, 641-669.

Berné, S., Trentesaux, A., Stolk, A., Missiaen, T., De Batist, M., 1994. Architecture and long term evolution of a tidal sandbank : The Middelkerke Bank (southern North Sea). Marine Geology 121, 57-72.

Bertin, X., Bruneau, N., Breilh, J.F., Fortunato, A.B., Karpytchev, M., 2012. Importance of wave age and resonance in storm surges : The case Xynthia, Bay of Biscay. Ocean Modelling 42, 16-30.

Bertin, X., Chaumillon, É., 2005. Apports de la modélisation sur bathymétries historiques dans la compréhension des évolutions des bancs de sable estuariens. Comptes Rendus Geoscience 337, 1375-1383.

Bertin, X., Chaumillon, E., Sottolichio, A., Pedreros, R., 2005. Tidal inlet response to sediment infilling of the associated bay and possible implications of human activities : the Marennes-Oléron Bay and the Maumusson Inlet, France. Continental Shelf Research 25, 1115-1131. 
Bertin, X., Li, K., Roland, A., Bidlot, J.R., 2015. The contribution of shortwaves in storm surges : Two case studies in the Bay of Biscay. Continental Shelf Research 96, 1-15.

Bertin, X., Oliveira, A., Fortunato, A.B., 2009. Simulating morphodynamics with unstructured grids : Description and validation of a modeling system for coastal applications. Ocean Modelling 28, 75-87.

Bertin, X., Prouteau, E., Letetrel, C., 2013. A significant increase in wave height in the North Atlantic Ocean over the 20th century. Global and Planetary Change 106, 77-83. Cited By 9.

Billeaud, I., Chaumillon, E., Weber, O., 2005. Evidence of a major environmental change recorded in a macrotidal bay (Marennes-Oléron Bay, France) by correlation between VHR seismic profiles and cores. Geo-Marine Letters 25, $1-10$.

Bosboom, J., Reniers, A., 2014. Displacement-based error metrics for morphodynamic models. Advances in Geosciences 39, 37-43.

Cayocca, F., 2001. Long-term morphological modeling of a tidal inlet : the Arcachon Basin, France. Coastal Engineering 42, 115-142.

Chaumillon, E., Bertin, X., Falchetto, H., Allard, J., Weber, N., Walker, P., Pouvreau, N., Woppelmann, G., 2008. Multi time-scale evolution of a wide estuary linear sandbank, the Longe de Boyard, on the French Atlantic coast. Marine Geology 251, 209-223.

Chaumillon, E., Féniès, H., Billy, J., Breilh, J.F., Richetti, H., 2013. Tidal and fluvial controls on the internal architecture and sedimentary facies of a lobate estuarine tidal bar (The Plassac Tidal Bar in the Gironde Estuary, France). Marine Geology 346, 58-72.

Chaumillon, E., Gillet, H., Weber, N., Tesson, M., 2002. Évolution temporelle et architecture interne d'un banc sableux estuarien : la Longe de Boyard (littoral atlantique, France). Comptes Rendus Geoscience 334, 119-126. 
Dalrymple, R.W., Rhodes, R.N., 1995. Estuarine dunes and bars. Geomorphology and sedimentology of estuaries 53, 359-422.

Dastgheib, A., Roelvink, J., Wang, Z., 2008. Long-term process-based morphological modeling of the Marsdiep Tidal Basin. Marine Geology 256, 90-100.

Dissanayake, D., Ranasinghe, R., Roelvink, J., 2009. Effect of sea level rise in tidal inlet evolution : A numerical modelling approach. Journal of Coastal Research , 942-946.

Dodet, G., 2013. Morphodynamic modelling of a wave-dominated tidal inlet : the Albufeira Lagoon. Ph.D. thesis.

Dodet, G., Bertin, X., Taborda, R., 2010. Wave climate variability in the NorthEast Atlantic Ocean over the last six decades. Ocean Modelling 31, 120-131.

Dyer, K.R., Huntley, D.A., 1999. The origin, classification and modelling of sand banks and ridges. Continental Shelf Research 19, 1285-1330.

Fortunato, A.B., Nahon, A., Dodet, G., Pires, A.R., Freitas, M.C., Bruneau, N., Azevedo, A., Bertin, X., Benevides, P., Andrade, C., et al., 2014. Morphological evolution of an ephemeral tidal inlet from opening to closure : the Albufeira inlet, Portugal. Continental Shelf Research 73, 49-63.

Geleynse, N., Storms, J., Stive, M., Jagers, H., Walstra, D., 2010. Modeling of a mixed-load fluvio-deltaic system. Geophysical Research Letters 37.

Geleynse, N., Storms, J.E., Walstra, D.J.R., Jagers, H.A., Wang, Z.B., Stive, M.J., 2011. Controls on river delta formation; insights from numerical modelling. Earth and Planetary Science Letters 302, 217-226.

Gómez, E.A., Perillo, G.M., 1992. Largo Bank : A shoreface-connected linear shoal at the Bahía Blanca Estuary entrance, Argentina. Marine Geology 104, 193-204. 
Gouriou, T., Míguez, B.M., Wöppelmann, G., 2013. Reconstruction of a twocentury long sea level record for the Pertuis d'Antioche (France). Continental Shelf Research 61, 31-40.

Guérin, T., Bertin, X., Dodet, G., 2016. A numerical scheme for coastal morphodynamic modelling on unstructured grids. Ocean Modelling 104, 45-53.

Harris, P.T., 1988. Large-scale bedforms as indicators of mutually evasive sand transport and the sequential infilling of wide-mouthed estuaries. Sedimentary Geology 57, 273-298.

Houbolt, J., 1968. Recent sediments in the southern bight of the North Sea. Geologie en mijnbouw 47, 245-273.

Huthnance, J., 1982. On one mechanism forming linear sand banks. Estuarine, Coastal and Shelf Science 14, 79-99.

Idier, D., Pedreros, R., Oliveros, C., Sottolichio, A., Choppin, L., Bertin, X., 2006. Contributions respectives des courants et de la houle dans la mobilité sédimentaire d'une plate-forme interne estuarienne. Exemple : le seuil interinsulaire, au large du pertuis d'Antioche, France. Comptes Rendus Geoscience $338,718-726$.

Kalnay, E., Kanamitsu, M., Kistler, R., Collins, W., Deaven, D., Gandin, L., Iredell, M., Saha, S., White, G., Woollen, J., Zhu, Y., Chelliah, M., Ebisuzaki, W., Higgins, W., Janowiak, J., Mo, K., Ropelewski, C., Wang, J., Leetmaa, A., Reynolds, R., Jenne, R., Joseph, D., 1996. The NCEP/NCAR 40-year reanalysis project. Bulletin of the American Meteorological Society 77, 437471. Cited By 13773.

Kapsimalis, V., Massé, L., Velegrakis, A., Tastet, J., Lagasquie, M., Paireau, O., 2004. Formation and growth of an estuarine sandbank : Saint-Georges Bank, Gironde Estuary (France). Journal of Coastal Research , 27-42. 
Komen, G.J., Cavaleri, L., Donelan, M., Hasselmann, K., Hasselmann, S., Janssen, P.A.E.M., 1996. Dynamics and Modelling of Ocean Waves. Cambridge University Press.

Larson, M., Camenen, B., Nam, P.T., 2011. A unified sediment transport model for inlet application. Journal of Coastal Research , 27-38.

Latteux, B., 1995. Techniques for long-term morphological simulation under tidal action. Marine Geology 126, 129 - 141. Large-Scale Coastal Behavior.

Le Hir, P., Cayocca, F., Waeles, B., 2011. Dynamics of sand and mud mixtures : a multiprocess-based modelling strategy. Continental Shelf Research 31, S135S149.

Leonard, B., 1991. The ULTIMATE conservative difference scheme applied to unsteady one-dimensional advection. Computer methods in applied mechanics and engineering 88, 17-74.

Ludwick, J.C., 1974. Tidal currents and zig-zag sand shoals in a wide estuary entrance. Geological Society of America Bulletin 85, 717-726.

Nahon, A., Bertin, X., Fortunato, A.B., Oliveira, A., 2012. Process-based 2DH morphodynamic modeling of tidal inlets : a comparison with empirical classifications and theories. Marine Geology 291, 1-11.

Olariu, M.I., Olariu, C., Steel, R.J., Dalrymple, R.W., Martinius, A.W., 2012. Anatomy of a laterally migrating tidal bar in front of a delta system : Esdolomada Member, Roda Formation, Tremp-Graus Basin, Spain. Sedimentology $59,356-378$.

Pattiaratchi, C., Collins, M., 1987. Mechanisms for linear sandbank formation and maintenance in relation to dynamical oceanographic observations. Progress in Oceanography 19, 117-176.

Reniers, A., Gallagher, E., MacMahan, J., Brown, J., Rooijen, A., Thiel de Vries, J., Prooijen, B., 2013. Observations and modeling of steep-beach grain-size variability. Journal of Geophysical Research : Oceans 118, 577-591. 
van Rijn, L., Soulsby, R., Hoekstra, P., Davies, A., 2005. SANDPIT, Sand

Transport and Morphology of Offshore Mining Pits. Aqua Publications.

van Rijn, L., Walstra, D., Ormondt, M.v., 2004. Description of TRANSPOR2004 and implementation in DELFT3D-ONLINE : final report. Technical Report. Deltares (WL).

van Rijn, L.C., 2007a. Unified View of Sediment Transport by Currents and Waves. I : Initiation of Motion, Bed Roughness, and Bed-Load Transport. Journal of Hydraulic Engineering 133, 649-667.

van Rijn, L.C., 2007b. Unified View of Sediment Transport by Currents and Waves. II : Suspended Transport. Journal of Hydraulic Engineering 133, 668689.

Roland, A., Zhang, Y.J., Wang, H.V., Meng, Y., Teng, Y.C., Maderich, V., Brovchenko, I., Dutour-Sikiric, M., Zanke, U., 2012. A fully coupled 3D wave-current interaction model on unstructured grids. Journal of Geophysical Research 117.

Signell, R.P., Harris, C.K., 2000. Modeling sand bank formation around tidal headlands, pp. 209-222.

Soulsby, R., 1997. Dynamics of marine sands : a manual for practical applications. Thomas Telford.

Swift, D., Phillips, S., Thorne, J., 1991. Sedimentation on continental margins, IV : lithofacies and depositional systems. Shelf Sand and Sandstone Bodies : Geometry, Facies and Sequence Stratigraphy , 89-152.

Tolman, H.L., others, 2009. User manual and system documentation of WAVEWATCH III TM version 3.14. Technical note, MMAB Contribution 276.

Toublanc, F., Brenon, I., Coulombier, T., Le Moine, O., 2015. Fortnightly tidal asymmetry inversions and perspectives on sediment dynamics in a macrotidal estuary (Charente, France). Continental Shelf Research 94, 42-54. 
Viparelli, E., Blom, A., Ferrer-Boix, C., Kuprenas, R., 2014. Comparison between experimental and numerical stratigraphy emplaced by a prograding delta. Earth Surface Dynamics 2, 323-338.

Walstra, D., Hoekstra, R., Tonnon, P., Ruessink, B., 2013. Input reduction for long-term morphodynamic simulations in wave-dominated coastal settings. Coastal Engineering 77, 57-70.

Wu, W., Lin, Q., 2014. Nonuniform sediment transport under non-breaking waves and currents. Coastal Engineering 90, 1-11.

Wu, W., Wang, S.S., Jia, Y., 2000. Nonuniform sediment transport in alluvial rivers. Journal of Hydraulic Research 38, 427-434.

Zhang, Y., Baptista, A.M., 2008. SELFE : A semi-implicit Eulerian-Lagrangian finite-element model for cross-scale ocean circulation. Ocean Modelling 21, 71-96. 